\title{
Study on Construction and Management of Multimedia Demonstration Classroom in Higher Vocational Colleges
}

\author{
Yun Fan \\ Tianjin Maritime College Tianjin 300350
}

Keywords: Higher vocational colleges; Multimedia classroom; Construction; Management

\begin{abstract}
With the rapid development of computer information technology and the process of quality education in Higher Vocational Colleges which are seemed as the base of national higher education places is advancing with the times using multimedia means to carry out teaching activities, and it achieved good results. This study from the current situation of the use of multimedia classroom in higher vocational colleges, summed up the problems in the process of construction and management, and finally put forward some countermeasures and suggestions on how to improve the construction management.

With rapid development of information technology in today, multimedia technology has matured, and multimedia teaching has become a major feature of modern education, which represents a development direction of modern education. With the rapid development of computer information technology and the process of quality education in Higher Vocational Colleges, more and more colleges and universities choose multimedia assisted means to carry out teaching activities. As a new form of teaching, teaching in multimedia demonstration classroom can be finished by media text, graphics, sound, video and other elements, so as to give the students to create a lively and vivid classroom atmosphere, enhance the enthusiasm of students to a large extent. In this view, a large number of Multimedia Demonstration Classroom such as bamboo shoots after a spring rain in number and size, showing a rising trend year by year. At the same time, after the multimedia classroom being put into use, problems in construction and management increase obviously, then how to optimize the allocation of resources in the construction process, which means in the process of management target, has become an urgent need to solve the problem of the multimedia classroom.
\end{abstract}

\section{Problems Existing in the Construction and Management of Multimedia Classroom in Higher Vocational Colleges}

Multimedia teaching refers to the application of multimedia technology, through collection, transmission, processing and sharing of multimedia teaching information to achieve the goal of teaching and learning. In the teaching activities, the use of computer and technology in the teaching process of information, to achieve the purpose of teaching and to complete the teaching task. With the continuous teaching of Higher Vocational Colleges and the teaching quality is an urgent need to promote the process of the construction and management of higher vocational colleges are increasingly committed to the multimedia classroom, but there are still weakness in the process of construction and the global consciousness, such as the lack of systematic management, funds, and

Problem of Construction. The construction of College Multimedia Demonstration Classroom is limited to a single function, not for overall planning, which means global awareness is weak, lack of system leading to so many multimedia classroom function repeats, and resource allocation is not reasonable. On the one hand, in the beginning of the construction of multimedia classrooms, higher vocational colleges did not plan. The construction of multimedia classroom has not stood in the school's development strategy pointing of reasonable design, but blindly follow the trend, with reference to other schools of design and construction, resulting in multimedia classroom's style and function between the institutions, professional generally identical, weakened the colleges own characteristics, and the lack of new ideas. At the same time, due to the construction of financial problems, the multimedia teaching in the same multimedia classroom will often carry different specialties, and because the professional focus is completely different, the function and 
configuration of multimedia classroom is not the same, which cannot be completely uniform, if the multimedia teaching room shall be in accordance with the high profile construction, it will cause the invisible idle and waste of resources, while if the low profile construction, and it is difficult to meet the professional needs of specific courses. On the other hand, there are many departments involved in the construction of multimedia classroom, and there are obvious problems in the coordination of the work. The construction of multimedia classroom equipment purchasing department, logistics department, technical service department and other departments to work together. Because of the various departments belong to different administrative units, so there is always mutual buck passing things in the construction process, which restricts the multimedia classroom in the construction process to a certain extent. For example, the projector equipment of purchasing department include Hitachi, MITSUBISHI, SONY and other brands, and technical services in the course of the experiment found that the machine control does not exactly match the connection system between each brand, in this kind of situation, equipment purchasing department shirks technical service department's technical installation and technical services department accuses the procurement of equipment with buying accessories. These two departments mutual shirk responsibility, each one sticks to his argument, but also makes the multimedia classroom construction schedule and quality greatly discount.

Problems of Management. The presentation of multimedia classroom management system is comprehensive, it needs many synergies between departments, but due to the lack of funds and system management and other reasons, there are more problems. Firstly, capital management of multimedia classroom is relatively deficient and lack of earmarking funds management, thus causing damage to the equipment after repair of long time. The multimedia classroom equipment accessories are consumables, during the long time of operation there will be some failures and damage, and some higher vocational colleges only equipped with multimedia classroom construction funds, while ignoring the long-term management and maintenance funds, making a lot of spare parts cannot be timely updated, thereby affecting the use effect of multimedia classroom. Secondly, in order to standardize the presentation of multimedia classroom management, higher vocational colleges have developed a detailed management plan, but in the actual teaching process, these Regulations are difficult to implement in place, if there are problems, mutual responsibility between each subject of liability blame each other, and the system is also a lack of executive force. Finally, the multimedia classroom management is a huge system engineering, as the clas sroom's numerous equipment, complex configuration, management and maintenance tasks, management initiative greatly discount, while part of teachers lack of responsibility who often free install software, some even after the end of classes do not shut down the computer equipment leave, resulting in frequent failures of mechanical equipment. A statistical data shows that the more $60 \%$ of the equipment failures are caused by human's error operation, which also brings greater difficulty to the management work.

\section{Countermeasures and Suggestions to Improve the Construction and Management of Multimedia Classroom}

Multimedia demonstration classroom plays an important role in the practical teaching activities, however, due to the existence of problems in the construction and management, the classroom teaching results have been influenced, so how to improve the construction and management of multimedia classroom, so that it can better service for teaching activities has become the current urgent problem in Higher Vocational colleges. According to its own practical experience, the author puts forward the following solutions and suggestions for the problems mentioned above.

Strategies and Suggestions for Improving the Construction of Multimedia Classroom. The construction of multimedia classroom should first standing at the school development under the overall planning, to design construction from a holistic perspective, and to reflect the characteristics of the subject of vocational colleges, avoid blindly copying. Firstly, multimedia classroom teaching should be made by the competent school leaders at the beginning of the construction, integration of technical services, equipment procurement department and other departments. And the project team 
is responsible for all processes in the construction of multimedia classroom. In this way, it can be handled in a timely manner to deal with the differences of opinion among various departments or the conflict of interest, so as to prevent the mutual shirks responsibility between departments. At the same time, the group in the construction plan is determined to organize experts and scholars and other persons held seminars, comprehensively evaluate the feasibility and practicability of the construction scheme to determine the benefit by mutual discussions. Secondly, select the unified model of multimedia classroom equipment. In the process of the construction of multimedia classroom and the actual situation of the school choice points, it should choose appropriate equipment configuration, the best selection of uniform computer and projector brand, which can not only to buy with the relative prices of equipment, but also conducive to the daily use and maintenance of equipment. Thirdly, rational planning of multimedia classroom. Multimedia classroom can be divided into simple type, standard type and professional type in the construction of demonstration multimedia classroom in higher vocational colleges. Because of these multimedia classrooms have different functions, so the investment in maintenance and management costs are not the same, which means according to their own situation and needs to choose reasonable curriculum planning and construction specifications and types of multimedia classroom, both to be able to satisfy the teaching needs of teaching activity and to reduce excessive investment funds.

Strategies and Suggestions for Strengthening the Management of Multimedia Classrooms. The management of multimedia classroom is a complicated systematic project, which involves many aspects, such as system, personnel and equipment. Firstly, it refers to in-depth implementation of the multimedia classroom management system, so that these systems can really be put in place. Managers should formulate feasible, and make multimedia classroom management system conforming to the reality to regular management of multimedia classroom training teachers and to standardize the use of multimedia equipment improving the ability of classroom teaching. Schools should also formulate the corresponding evaluation system to evaluate the training results of teachers, to ensure that the system can be implemented. In addition, the school also should establish a feedback mechanism of flow problems, once the teacher found the problem, he can give feedback to the maintenance and management of personnel through the message, log, and repair the equipment in the shortest possible time to reduce the injury of delay. Secondly, the regional division of responsibilities and solve the problem of centralized management. Multimedia classroom management modes are not the same in different higher vocational colleges, which can be mainly divided into the centralized management of the college, the Department of management, decentralized and centralized management and so on. No matter what kind of management mode, it should realize different departments and individuals face the regional division of responsibilities to achieve fine management and solve the problem of centralized management, so as to avoid the mutual shirk responsibility of various departments and professional. Finally, strengthen the daily management of the core equipment. In the multimedia classroom, the core equipment mainly includes the central control system, the computer, the projector and so on. The control system is generally relatively stable, which usually does not have a failure that can be maintenance free in a long time. Computer and projector equipment belongs to consumables, prone to failure in the process of using, so colleges should strengthen its management. Each computer multimedia classroom and projector will suggest corresponding equipment ledger and maintenance files for easy damaged parts to carry out regular maintenance, such as projector in multimedia classroom checking the screen, LCD panel and lighting to ensure working performance of mechanical equipment.

In a word, with the development of higher vocational colleges, the number of multimedia demonstration classroom will be more and more, and the multimedia classroom construction management still exist many problems which plays a very important role on the effectiveness of classroom teaching. Therefore, higher vocational colleges should make overall planning, implement the system, comprehensively strengthen the construction and management of multimedia classrooms giving full play to the role of the multimedia classroom, and improve steadily the quality of teaching. 


\section{References}

[1] Lei Haiyan. Construction and management of multimedia classroom in University of technology and application of $[\mathrm{J}]$ network security, 2014 (15)

[2] Huang Xiaodong. Construction and management of multimedia classroom in Higher Vocational Colleges [J] science and technology education, 2015 (16)

[3] Shen Aitao, construction and management of multimedia classroom in Colleges and universities [J] computer knowledge and technology, 2013 (02) 